Association for Information Systems

AIS Electronic Library (AISeL)

\title{
Bridging the Gap - An Analysis of Requirements for Performance Measurement Systems in Digital Innovation Units
}

\author{
Thomas Haskamp \\ Hasso-Plattner-Institut \\ Annalena Lorson \\ Hasso-Plattner-Institut \\ Danielly de Paula \\ Hasso-Plattner-Institut \\ Falk Uebernickel \\ Hasso-Plattner-Institut
}

Haskamp, Thomas; Lorson, Annalena; de Paula, Danielly; and Uebernickel, Falk, "Bridging the Gap - An Analysis of Requirements for Performance Measurement Systems in Digital Innovation Units" (2021). Wirtschaftsinformatik 2021 Proceedings. 8.

https://aisel.aisnet.org/wi2021/FITStrategy19/Track19/8

This material is brought to you by the Wirtschaftsinformatik at AIS Electronic Library (AISeL). It has been accepted for inclusion in Wirtschaftsinformatik 2021 Proceedings by an authorized administrator of AIS Electronic Library (AISeL). For more information, please contact elibrary@aisnet.org. 


\title{
Bridging the Gap - An Analysis of Requirements for Performance Measurement Systems in Digital Innovation Units
}

\author{
Thomas Haskamp ${ }^{1}$, Annalena Lorson ${ }^{1}$, Danielly de Paula ${ }^{1}$, Falk Uebernickel ${ }^{1}$ \\ ${ }^{1}$ Hasso Plattner Institute, Chair for Design Thinking and Innovation Research, University of \\ Potsdam, Potsdam, Germany \\ \{thomas.haskamp,annalena.lorson,danielly.depaula,falk.uebernickel\}@hpi.de
}

\begin{abstract}
Due to a rapidly changing business environment, companies feel under constant pressure to innovate. In response to this challenge, and to accelerate their digital innovation endeavours, many incumbent firms set up Digital Innovation Units. To assess the effectiveness of these units, scholars and practitioners have called for the need to develop adequate means of measuring performance. This paper, therefore, reviews the literature on Performance Measurement Systems for Digital Innovation Units, and derives nine requirements. Conducting five case studies of Digital Innovation Units, we investigate the level of adoption of these requirements and propose three additional ones for a Performance Measurement System for innovation activities in Digital Innovation Units. We discuss these requirements and explain the reasons for their different levels of adoption. Thus, we contribute to literature and practice with a more adequate way of evaluating the performance of Digital Innovation Units, valuable to researchers and managers.
\end{abstract}

Keywords: Digital Innovation, Digital Innovation Unit, Performance Measurement System (Requirements)

\section{$1 \quad$ Introduction}

Digital Innovation presents a new paradigm and challenges the way we create innovation in firms [1]. One upcoming approach of reorganizing innovation for incumbent firms - which are especially challenged by new market entrants [2] - are Digital Innovation Units (DIU). These are organisational setups intended to initiate and develop digital innovation of various types [3]. While DIUs are gaining increasing attention in both academia $[4,5]$ and practice [6], there has been no agreement yet on their definition, only on several of their key characteristics. Accordingly, DIUs are dedicated and specialized (digital) units [7], separated from the main organisation in terms of location, mindset, collaboration, and communication. At the same time, they still remain "connected through the transfer of knowledge, exchange mechanisms, and people moving between the new and 'old' units" [3]. In this paper, we follow the definition proposed by Barthel et al. [5] which focuses on DIUs as "organisational units 
with the overall goal to foster organisational digital transformation by performing digital innovation activities for existing and novel business areas". Until now, research on the success or performance of DIUs in creating value is rare to non-existent [5]. Conversely, one of the reasons for their failure or abolishment, as identified in a recent study by Raabe et al. [8], is the lack of clarity surrounding the objectives that a DIU has been given. Both the lack of research and the clarity of their objectives underline the need for a Performance Measurement System capable of capturing the value contribution of DIUs. The difficulty here, however, lies in the very nature of the activities of DIUs. By definition, innovation is a very exploratory research area, associated with the early stages of innovation, where projects are subject to high uncertainty [9]. In addition to procedural challenges, the characteristics of digital innovation imply that other forms of measurement are required in addition to those already used by firms [10]. For example, the customer perspective on a specific digital product or service is becoming increasingly important, but has so far not been adequately represented by a key performance indicator [11]. While the literature has already analysed requirements for measuring innovation activities [12], and specifically looked at designing Performance Measurement Systems (PMS) in the context of ambidexterity [13-15], research is limited when it comes to combining the necessity of rethinking measurement efforts for early digital innovation activities $[5,10]$. Therefore, this paper aims to investigate the specific requirements of a PMS for innovation activities in DIUs and the current state of awareness and operationalisation in practice. For this purpose, the following research questions are addressed:

- $\quad$ [RQ1] Based on the literature, what are the existing requirements for a PMS relevant to DIUs, and how are these currently adopted in practice?

- $\quad$ [RQ2] What are the specific requirements for a PMS to measure the innovation activities of DIUs?

To answer the first part of RQ1, we review and synthesize the existing literature on PMS, from which we derive a set of requirements relevant to DIUs along three different streams: Requirements for PMS in general (equally applicable to digital innovation and agile performance measurement), requirements for PMS specifically relevant in the area of innovation, and special requirements for PMS for digital innovation and agile working. Subsequently, we use a multiple case study to examine practitioners' awareness of these theoretical requirements and provide initial insights on the status quo of their operationalization - answering the second part of RQ1 - as well as identify three new requirements - answering RQ2. In this way, we aim to contribute to both performance measurement and DIU research by bringing them closer together while focusing on the challenging area of early innovation activities. From the perspective of PMS research, we create the basis for the development of a PMS that can capture the complexity of the early innovation activities and recognize the impact of digital innovation on the measurement process. From a DIU research perspective, we take a first step in the challenging direction of measuring their success, which has already been raised in previous papers $[4,5]$. 


\section{Related Work - Measuring Digital Innovation}

In today's world, more than ever before, new digital ventures constantly challenge incumbent firms in various industries to keep up the speed and agility of developing customer-centric products and services [2]. To remain competitive, companies need to be able to successfully develop and implement innovations related to digital products, services, processes, and business models - so-called digital innovation [16]. Current research conceptually differentiates between innovation that is enabled by information technology (IT) ('IT-enabled innovation') and digital innovation [16]. IT-enabled innovation refers to the situation where an organisation imports an existing artifact, which it assimilated into the organisational context. Digital innovation - the focus of this paper - has been conceptualised by Yoo et al., for example, as "the carrying out of new combinations of digital and physical components to produce novel products" [1]. Managing and effectively orchestrating digital innovation is a complex task, which requires appropriate practices, processes, and principles [17]. In recent years, the digital innovation has increasingly been enabled through the implementation of separate 'fast lanes', often in the form of DIUs [7, 18, 19]. DIUs foster (digital) innovation by bundling a firm's exploration efforts and by adopting special practices such as agile methods (e.g., Scrum) or exploratory methods (e.g., Design Thinking) [3, 7, 8]. With the proliferation of DIUs, research contributions on the topic are also increasing [3-5, 7]. However, the literature still lies in its infancy, and notably the very central question of the efficiency and benefits of DIUs has not yet been addressed. Research already calls for contributions on that topic and Frey et al. [20] and Hund et al. [4], amongst others, raise the specific difficulties of measuring digital innovation outcomes in general and the necessity to deal with this topic $[4,5,10,20]$. Potential explanations for these difficulties are diverse [21]. Firstly, research has pointed out that, compared to traditional innovation, digital innovation has different characteristics, which requires measurement techniques to be adjusted accordingly $[10,16]$. Secondly, due to their exploratory nature, DIUs are often active in the early phases of the innovation process $[5,22]$, which is also the most uncertain part of that process, covering aspects such as opportunity identification, opportunity analysis, idea genesis, idea selection and concept, and technology development [9]. Attempting to carry out measurement in these contexts is particularly challenging as activities rarely follow predefined processes and therefore metrics are hard to define [23]. Furthermore, the currently low state of maturity of the concept of DIUs might explain why the question of measurement has not yet been addressed [5].

A PMS is usually set up to deal with these challenges. PMSs are information systems that help organisations with the collection, recording, analysis, and presentation of data for control purposes [12]. While the role of such systems - sometimes also termed "management control systems" - has long been seen as detrimental to innovation [14], scholars nowadays have recognized the potential of measurement efforts. Depending on their design, PMSs can facilitate information exchange in teams and align them to their goals [15]. From an Information System's (IS) perspective, research stresses the capacity of IS to reduce the effort of data collection associated with the innovation processes [13]. Beyond this, IS could provide new capabilities for management as 
"data become accurate, shareable, and available to different parties without creating the panoptic dream of visibility and action at a distance" [24]. However, while PMS could add value to the measurement of DIU activities, their role in the context of digital innovation currently remains underexplored and open to discussion [10].

\section{$3 \quad$ Methodology}

To answer RQ1, we first conducted a literature review to identify any existing requirements for PMS that are relevant to DIUs. We then used a multiple case study design to examine the awareness and the operationalisation of these requirements in practice. With these case studies we were able to detect three additional requirements for PMS in the context of DIUs that had not yet been considered in the literature - or if so, only insufficiently - thus answering RQ2.

\subsection{Literature Review}

To investigate the existing requirements, we conducted a literature review, following vom Brocke [25]. Thus, the first step was to define the review of the scope and to conceptualise the topic accordingly. Since DIUs apply agile working practices as an integral part of their innovation endeavours, as mentioned above, we have chosen not only to use the search terms "(digital) innovation" and "PMS", but also to include "agile" as a key word $[3,5]$. We then conducted a search looking for a keyword combination of 'Performance Measurement' and 'Agile', 'Performance Measurement' and 'Innovation' as well as 'Performance Measurement' and 'Digital Innovation' in the title, keywords or abstract of the databases EBSCOhost Business Source Complete, Web of Science, Scopus, JSTOR, WISO and AIS eLibrary. In total, we obtained 578 hits after the initial search. In a second step, we filtered all papers with an A+, A or B ranking in the German VHB-JOURQUAL3 and ended up with 58. The subsequent backward search yielded ten more hits, leading to a total of 68 papers that we read in detail, removing those with no clear connection to either (digital) innovation- and/or agile performance measurement. In the final step we analysed the remaining 21 papers and synthesised the requirements for (digital) innovation and agile PMS along three streams: 1) Requirements for PMS in general (equally applicable to digital innovation and agile performance measurement), 2) requirements for PMS specifically relevant in the area of innovation, and 3) special requirements for PMS for digital innovation and agile working.

\subsection{Multiple Case Study}

In order to determine the requirements for a PMS of DIUs, we have chosen an explorative, qualitative-empirical research approach by carrying out five case studies, which are particularly suitable for more recent phenomena that should be investigated in their real-world context [26]. We decided on a multiple-case design to enable crosscase analysis and to increase the overall robustness of the study [26]. Table 1 provides 
Table 1. Overview of the sample

\begin{tabular}{|c|c|c|c|c|c|}
\hline Case & $\begin{array}{l}\text { Size*, } \\
\text { Industry }\end{array}$ & $\begin{array}{l}\text { DIU Size }{ }^{* *} \text {, } \\
\text { Founded in }\end{array}$ & $\begin{array}{l}\text { DIU Objective and } \\
\text { Scope }^{* * *}\end{array}$ & $\begin{array}{l}\text { DIU gover- } \\
\text { nance and } \\
\text { structure } \\
\text { **** }\end{array}$ & $\begin{array}{l}\text { Interview } \\
\text { Partner Position } \\
\text { (No. Interviews) }\end{array}$ \\
\hline A & $\begin{array}{l}\text { Medium, } \\
\text { Consumer } \\
\text { Goods }\end{array}$ & $\begin{array}{l}\text { Medium, } \\
2018\end{array}$ & $\begin{array}{l}\text { 1) Primarily internal } \\
\text { 2) Existing business } \\
\text { 3) Idea generation, } \\
\text { Idea selection, } \\
\text { Innovation } \\
\text { development }\end{array}$ & $\begin{array}{l}\text { 1) Balanced } \\
\text { 2) Integrated }\end{array}$ & $\begin{array}{l}\text { Head of Inno- } \\
\text { vation Lab (2), } \\
\text { Director Business } \\
\text { Development (2), } \\
\text { Innovation } \\
\text { Manager (1) }\end{array}$ \\
\hline B & $\begin{array}{l}\text { Upper } \\
\text { Large, } \\
\text { Insurance }\end{array}$ & $\begin{array}{l}\text { Medium, } \\
2015\end{array}$ & $\begin{array}{l}\text { 1) Primarily internal } \\
\text { 2) Existing and novel } \\
\text { business } \\
\text { 3) Innovation imple- } \\
\text { mentation and innova- } \\
\text { tion commercialization }\end{array}$ & $\begin{array}{l}\text { 1) Relatively } \\
\text { high } \\
\text { 2) Integrated }\end{array}$ & $\begin{array}{l}\text { Head of Open } \\
\text { Innovation (1) }\end{array}$ \\
\hline $\mathrm{C}$ & $\begin{array}{l}\text { Upper } \\
\text { Large, } \\
\text { Mobility }\end{array}$ & $\begin{array}{l}\text { Large, } \\
2014\end{array}$ & $\begin{array}{l}\text { 1) Primarily internal } \\
\text { 2) Existing and novel } \\
\text { business } \\
\text { 3) Idea generation, } \\
\text { Idea selection, Inno- } \\
\text { vation development, } \\
\text { Innovation implement- } \\
\text { tation, Innovation } \\
\text { commercialization }\end{array}$ & $\begin{array}{l}\text { 1) Relatively } \\
\text { high } \\
\text { 2) Separate } \\
\text { legal entity }\end{array}$ & $\begin{array}{l}\text { Venture } \\
\text { Developer (1) }\end{array}$ \\
\hline D & $\begin{array}{l}\text { Medium, } \\
\text { Real } \\
\text { Estate }\end{array}$ & $\begin{array}{l}\text { Small, } \\
2018\end{array}$ & $\begin{array}{l}\text { 1) Primarily internal } \\
\text { 2) Existing business } \\
\text { 3) Idea generation, } \\
\text { Idea selection, Inno- } \\
\text { vation development }\end{array}$ & $\begin{array}{l}\text { 1) Balanced } \\
\text { 2) Separate } \\
\text { department }\end{array}$ & $\begin{array}{l}\text { Innovation Mana- } \\
\text { ger (1), Head of } \\
\text { Innovation (1), } \\
\text { Project Manager } \\
\text { (3) }\end{array}$ \\
\hline E & $\begin{array}{l}\text { Large, } \\
\text { Energy }\end{array}$ & $\begin{array}{l}\text { Large, } \\
2017\end{array}$ & $\begin{array}{l}\text { 1) Primarily external } \\
\text { 2) Novel business } \\
\text { 3) Idea selection, Inno- } \\
\text { vation development, } \\
\text { Innovation implemen- } \\
\text { tation, Innovation } \\
\text { commercialization }\end{array}$ & $\begin{array}{l}\text { 1) Relatively } \\
\text { high } \\
\text { 2) Separate } \\
\text { department }\end{array}$ & $\begin{array}{l}\text { Venture Architect } \\
\text { (2), UX-Designer } \\
\text { (2) }\end{array}$ \\
\hline
\end{tabular}

*Size: Small $=<1 \mathrm{k}$ FTE \& revenue $<100$ Mio $€$ Medium $=>1 \mathrm{k}$ FTE \& revenue $<100$ Mio $€$; Large $=>1 \mathrm{k}$ FTE \& revenue $1-5 \mathrm{~B} €$; Upper Large $=>20 \mathrm{k}$ FTE \& revenue $>5 \mathrm{~B} \in ; * *$ DIU size (number of full time equivalent [FTE]): Small $=<6$; Medium $=6-15 ;$ Large $>15 ; * * * 1)$ Innovation orientation 2) Market focus of innovation 3) Scope of innovation. Criteria derived from [5, 7]; **** 1) Degree of freedom 2) Embedding. Criteria derived from $[3,7]$ : the degree of freedom (very low, relatively low, in balance, relatively high, very high), Embedding (integrated, separated department, separate legal entity, virtual)

an overview of the sample. In the selected cases, DIUs have been implemented by German and Swiss companies as part of their organisational digital transformation for at least two years to ensure that the operations of the units extend beyond their 
conceptualisation. We aimed for diverse cases - particularly in terms of types of industry, size, objective, and scope of the DIU - to generate contrasting results and thereby enhance the study's external validity [26]. Along with the five cases, we conducted 16 interviews between February and August 2020 with DIU employees following a semi-structured interview guide. The interview guide explored issues such as the way in which the DIU actually measures and monitors its progress in specific projects, but also on an overall basis, meaning how the DIU reports progress to the main organisation. Interviews and analysis of company data quickly revealed that many DIUs have a variety of elements for measuring their efforts but a specific PMS is missing, which encouraged us to delve deeper into possible measurement methods. Thus, after initial coding of the first two interviews for cases B and C following Gioia methodology [27], it was decided to use them as training cases to sharpen our interview guide. Here the coding was undertaken by one researcher while another validated the resulting coding table. For the following cases A, D, and E we conducted at least four interviews each used the iterated semi-structured questionnaire to capture different nuances of the application of a PMS in DIUs. We interviewed people with presumably good knowledge of DIU activities, such as the Head of Innovation (Lab), Innovation Managers, Project Managers, etc. The interviews were conducted via telephone in the native language of the participants - as interviewees should be able to express their thoughts in a comfortable way - and lasted 51 minutes on average. Translation into English took place after coding by researchers with advanced skills in the English language. The results were validated through internal discussions within the research team. All interviews were recorded and transcribed verbatim [28]. For the data triangulation we gathered secondary data including information from firm websites, press releases and internal documents (e.g., management reports, excel sheets with metrics) [26]. We used ATLAS.ti to collect, store, and analyse our data [26, 28].

\section{$4 \quad$ Results}

We present our results in three subsections: First, we give an overview of the requirements from literature, presenting them along three streams to lay the foundation for RQ1. Second, we provide an overview of the awareness and the operationalisation of these requirements in the cases, in contribution to the second part of RQ1. Third, we propose three new requirements that have emerged from the data analysis of the five case studies, thus answering RQ2.

\subsection{Requirements from Literature Review}

From our literature review, we were able to derive requirements based on three streams: 1) Requirements that are relevant to PMS in general, and thus also to (digital) innovation and agile performance measurement, 2) requirements for PMS specifically relevant to innovation, and 3) requirements for PMS specifically relevant to digital innovation and agile working. The first stream comprises four requirements and is based on a total of eight papers. The second stream includes three requirements 
originating from ten papers. The third stream contains two requirements from seven papers. The results of our literature review are shown in Table 2.

Table 2. Overview of requirements for a PMS in literature

\begin{tabular}{|c|c|c|}
\hline Stream & No & Requirement \\
\hline \multirow{4}{*}{$\begin{array}{l}\text { 1) Require- } \\
\text { ments } \\
\text { relevant to } \\
\text { PMS in } \\
\text { general }\end{array}$} & RE1 & $\begin{array}{l}\text { PMS should allow its user to generate insights for decision-making in } \\
\text { innovation projects. This requires the availability of data that can be } \\
\text { contextualized (e.g., through benchmarks, targets, etc.) which implies that the } \\
\text { user can derive implications for taking action [29-32]. }\end{array}$ \\
\hline & RE2 & $\begin{array}{l}\text { PMS should allow high ease of use for different stakeholders and functional } \\
\text { groups (main organisation, DIU management, DIU teams) which may have } \\
\text { specific expectations towards data and their representation }[12,33,34] \text {. }\end{array}$ \\
\hline & RE3 & $\begin{array}{l}\text { PMS should align the performance criteria with the corporate strategy and } \\
\text { select them from its objectives }[29,30] \text {. }\end{array}$ \\
\hline & RE4 & $\begin{array}{l}\text { PMS should allow for easy data collection following actual activities that take } \\
\text { place in the organisation }[12,35] \text {. }\end{array}$ \\
\hline \multirow{3}{*}{$\begin{array}{l}\text { 2) Require- } \\
\text { ments for } \\
\text { PMS spe- } \\
\text { cifically } \\
\text { relevant to } \\
\text { innovation }\end{array}$} & RE5 & $\begin{array}{l}\text { PMS should distinguish between different innovation intentions (e.g., radical vs } \\
\text { incremental, process vs product) and their required mode of control }[13,14,36- \\
39] \text {. }\end{array}$ \\
\hline & RE6 & $\begin{array}{l}\text { PMS should allow for the use of different measurement techniques (e.g., focus } \\
\text { on input, output, process) and performance dimensions (e.g., Learning and } \\
\text { Knowledge, Financial) along with different innovation phases (e.g., idea } \\
\text { generation, idea selection, idea development) }[34,35,39] \text {. }\end{array}$ \\
\hline & RE7 & $\begin{array}{l}\text { PMS should contain the opportunity to process both quantitative data (e.g., } \\
\text { number of interviews, FTEs employees) and qualitative data (e.g., user insights, } \\
\text { Customer Satisfaction) during the innovation process }[36,40,41] \text {. }\end{array}$ \\
\hline \multirow{2}{*}{$\begin{array}{l}\text { 3) Require- } \\
\text { ments for } \\
\text { PMS for } \\
\text { digital } \\
\text { innovation } \\
\text { and agile } \\
\text { working }\end{array}$} & RE8 & $\begin{array}{l}\text { PMS should be more closely aligned with the digital innovation process, as the } \\
\text { role of IT has changed from measuring an IT department to an integral part of } \\
\text { the overall business strategy, which requires greater customer-centricity as well } \\
\text { as proximity to market and therefore new metrics }[10,11,42,43] \text {. }\end{array}$ \\
\hline & RE9 & $\begin{array}{l}\text { PMS should follow the logic of agile methods (e.g., Scrum) and exploratory } \\
\text { methods (e.g., Design Thinking) which rely on shorter cycle times and are more } \\
\text { responsive to upcoming changes }[21,44-46] \text {. }\end{array}$ \\
\hline
\end{tabular}

\subsection{Requirements from Literature found in Cases}

Based on the requirements found in the literature, we examined if these were operationalised in the specific company context of DIUs (see Table 3). Here we distinguish between three categories: "Not Mentioned", "Aware, but Not Operationalised" and "Operationalised". The category "Not Mentioned" means that we could not find any reference to this particular requirement in the materials available (e.g., interviews, internal documents). "Aware, Not Operationalised" implies that the interviewees did mention this requirement - and potentially considered it as being important - but have not yet been able to present any concrete approaches for its 
implementation. "Operationalised" are all those requirements for which proof of detailed implementation is available in the form of specific documents (Excel sheets, reports, etc.) or concrete interview statements. When presenting our results, we specifically focus on the category "Aware, Not Operationalised", as its detailed consideration seems to be most fruitful. "Not Mentioned" is mainly found in cases where the number of interviews was limited and, therefore, we decided to use them as training cases to specific the interview guide. If a requirement is marked as "Operationalised", we are looking at a simple confirmation of knowledge from the literature, which has no real degree of novelty. By looking at "Aware, Not Operationalised" we hope to gain insights into particularities of PMS implementation in the specific context of a DIU.

Requirements relevant for PMS in general

The requirement RE1, was operationalised in one case (E). In three other cases (A, B, D) the requirement was known, but had not yet been implemented. For example, one of the interviewees in Case A explicitly mentioned the importance of benchmarking data that could help to contextualise the DIUs efforts and identify implications: "The benchmark is really exciting. It allows you to measure your own success against others and take concrete measures. The cross comparison would certainly help us. It would support us internally before the management and the board of directors. Externally you can then compare yourself with other companies." For the second requirement RE2, three cases indicated that they were aware of it but had not yet operationalised it: "I wonder who this dashboard is talking to. The upper management surely likes dashboards. But for me, the important knowledge is [...] rather qualitative." (Case E). The quote shows that in actual projects, teams often rely on qualitative expectations, while management looks for quantitatively comparable metrics. The relevance of RE3, was recognised in all five cases and has already been implemented in three (Cases A, B, D). However, the opinions of the interviewees differ to some extent. While one person - whose DIU fulfils RE3 - stated the relevance of this topic: "When you present the whole thing in front of a board, in addition to these KPIs you need to understand if the project fits into the strategic context." (Case B), a member from a different DIU which has not implemented RE3 - seemed much more critical about it considering the early stage of his innovation project: "In my opinion, measuring strategic goals in the early stages is a waste of time. The founder is there for me to integrate the vision - he has to notice when the vision is not followed." (Case C). RE4 was found to be implemented twice (Cases A and E), while being on the radar of a third DIU (Case D). The fact that it is still a challenge to collect data with high validity and objectivity even for DIUs that had already operationalised RE4 - is shown by the following quote: "I wonder how the data is created in this tool. The numbers must be realistic, so the data should not be entered by a person." (Case A).

Requirements for PMS specifically relevant to innovation

The fifth requirement, specifically addressing different innovation intentions and their required modes of control, was operationalised by two DIUs (Cases A and C). Although Cases D and $\mathrm{E}$ are also aware of the need for this requirement, no implementation has taken place so far. Case D, for example, distinguishes between three types of innovation intentions - products, services and internal process improvements: "[o]ne is actual 
Table 3. Awareness and operationalization of requirements for a DIU PMS in practice

\begin{tabular}{|c|c|c|c|c|c|c|}
\hline Stream & No & A & B & $\mathrm{C}$ & $\mathrm{D}$ & $\mathrm{E}$ \\
\hline \multirow{4}{*}{$\begin{array}{l}\text { 1) Require- } \\
\text { ments } \\
\text { relevant for } \\
\text { PMS in } \\
\text { general }\end{array}$} & RE1 & $\begin{array}{l}\text { Aware, } \\
\text { Not Opera- } \\
\text { tionalised } \\
\end{array}$ & $\begin{array}{l}\text { Aware, } \\
\text { Not Opera- } \\
\text { tionalised }\end{array}$ & $\begin{array}{l}\text { Not } \\
\text { Mentioned }\end{array}$ & $\begin{array}{l}\text { Aware, } \\
\text { Not Opera- } \\
\text { tionalised }\end{array}$ & $\begin{array}{l}\text { Opera- } \\
\text { tionalised }\end{array}$ \\
\hline & RE2 & $\begin{array}{l}\text { Aware, } \\
\text { Not Opera- } \\
\text { tionalised }\end{array}$ & $\begin{array}{l}\text { Not } \\
\text { Mentioned }\end{array}$ & $\begin{array}{l}\text { Not } \\
\text { Mentioned }\end{array}$ & $\begin{array}{l}\text { Aware, } \\
\text { Not Opera- } \\
\text { tionalised }\end{array}$ & $\begin{array}{l}\text { Aware, } \\
\text { Not Opera- } \\
\text { tionalised }\end{array}$ \\
\hline & RE3 & $\begin{array}{l}\text { Opera- } \\
\text { tionalised }\end{array}$ & $\begin{array}{l}\text { Opera- } \\
\text { tionalised }\end{array}$ & $\begin{array}{l}\text { Aware, } \\
\text { Not Opera } \\
\text { tionalised }\end{array}$ & $\begin{array}{l}\text { Opera- } \\
\text { tionalised }\end{array}$ & $\begin{array}{l}\text { Aware, } \\
\text { Not Opera- } \\
\text { tionalised }\end{array}$ \\
\hline & RE4 & $\begin{array}{l}\text { Opera- } \\
\text { tionalised }\end{array}$ & $\begin{array}{l}\text { Not } \\
\text { Mentioned }\end{array}$ & $\begin{array}{l}\text { Not } \\
\text { Mentioned }\end{array}$ & $\begin{array}{l}\text { Aware, } \\
\text { Not Opera- } \\
\text { tionalised }\end{array}$ & $\begin{array}{l}\text { Opera- } \\
\text { tionalised }\end{array}$ \\
\hline \multirow{3}{*}{$\begin{array}{l}\text { 2) Require- } \\
\text { ments for } \\
\text { PMS } \\
\text { specifically } \\
\text { relevant in } \\
\text { the area of } \\
\text { innovation }\end{array}$} & RE5 & $\begin{array}{l}\text { Opera- } \\
\text { tionalised }\end{array}$ & $\begin{array}{l}\text { Not } \\
\text { Mentioned }\end{array}$ & $\begin{array}{l}\text { Opera- } \\
\text { tionalised }\end{array}$ & $\begin{array}{l}\text { Aware, } \\
\text { Not Opera- } \\
\text { tionalised }\end{array}$ & $\begin{array}{l}\text { Aware, } \\
\text { Not Opera- } \\
\text { tionalised }\end{array}$ \\
\hline & RE6 & $\begin{array}{l}\text { Opera- } \\
\text { tionalised }\end{array}$ & $\begin{array}{l}\text { Opera- } \\
\text { tionalised }\end{array}$ & $\begin{array}{l}\text { Opera- } \\
\text { tionalised }\end{array}$ & $\begin{array}{l}\text { Opera- } \\
\text { tionalised }\end{array}$ & $\begin{array}{l}\text { Opera- } \\
\text { tionalised }\end{array}$ \\
\hline & RE7 & $\begin{array}{l}\text { Aware, } \\
\text { Not Opera- } \\
\text { tionalised }\end{array}$ & $\begin{array}{l}\text { Opera- } \\
\text { tionalised }\end{array}$ & $\begin{array}{l}\text { Opera- } \\
\text { tionalised }\end{array}$ & $\begin{array}{l}\text { Aware, } \\
\text { Not Opera- } \\
\text { tionalised }\end{array}$ & $\begin{array}{l}\text { Opera- } \\
\text { tionalised }\end{array}$ \\
\hline \multirow{2}{*}{$\begin{array}{l}\text { 3) Require- } \\
\text { ments for } \\
\text { PMS for } \\
\text { digital } \\
\text { innovation } \\
\text { and agile } \\
\text { working }\end{array}$} & RE8 & $\begin{array}{l}\text { Aware, } \\
\text { Not Opera- } \\
\text { tionalised }\end{array}$ & $\begin{array}{l}\text { Opera- } \\
\text { tionalised }\end{array}$ & $\begin{array}{l}\text { Not } \\
\text { Mentioned }\end{array}$ & $\begin{array}{l}\text { Opera- } \\
\text { tionalised }\end{array}$ & $\begin{array}{l}\text { Aware, } \\
\text { Not Opera- } \\
\text { tionalised }\end{array}$ \\
\hline & RE9 & $\begin{array}{l}\text { Opera- } \\
\text { tionalised }\end{array}$ & $\begin{array}{l}\text { Not } \\
\text { Mentioned }\end{array}$ & $\begin{array}{l}\text { Opera- } \\
\text { tionalised }\end{array}$ & $\begin{array}{l}\text { Aware, } \\
\text { Not Opera- } \\
\text { tionalised }\end{array}$ & $\begin{array}{l}\text { Aware, } \\
\text { Not Opera- } \\
\text { tionalised }\end{array}$ \\
\hline
\end{tabular}

products [...]. You measure this very differently than a service. The second is ideas for new services. And the third are internal process improvements." - for which different metrics have not yet been defined. For requirement RE6, we see an implementation in all five DIUs considered. Thus, in all DIUs different dimensions were measured based on a holistic approach, as the following example shows: "A lab is about bringing together different perspectives; the technological view, the customer's view and the economic view. So, these KPIs are relevant to us." (Case A). RE7 has not yet been operationalised in cases A and D, although its relevance was recognised. One of the interviewees in Case D for example made a connection between the measurement approach (qualitative/quantitative) and the project intention (type and phase of project): "[...] we should continue to monitor the projects for five years afterwards. For example, how many offers were sent out as a result, how many orders were actually received and how much money was generated [...]. And then [...] we had a project; it was really more about finding out what the customers actually want nowadays [...]. 
And there were no orders afterwards. [...] That's why there is another side to it. And that's why it was more about the soft facts, like how did the customers react, employee satisfaction, maybe we achieved an image improvement, competence building, etc."

Requirements for all PMS for digital innovation and agile working

While the necessity of RE8, was recognized by four of the DIUs considered, Cases A and $\mathrm{E}$ do not yet implement the requirement. A DIU member from case A reflected on its challenges: "I realize that in the classical and physical development world certain KPIs and methods make sense, and in the digital world other KPIs and methods make sense. As an industry we bring hardware and software together." (Case A). The ninth and last requirement - RE9 - that we investigate, was also recognised by four of the DIUs considered, however not implemented by Cases D and E. The challenges regarding RE9 in practice were expressed by an interviewee from Case $\mathrm{E}$ who regularly works with design sprints and wondered how to set up a PMS that is dynamic enough to change with each sprint: "My question would be whether this data changes much from sprint to sprint."

In summary, we found that the DIUs in our case study had already been able to operationalise some of the requirements we derived from literature, but there are still some challenges that not everyone has been able to overcome yet. Especially RE1 and RE2 seem to be difficult to implement. Also, when excluding training cases B and C, the operationalisation of the requirements RE5, RE7, RE8 and RE9 - operationalised by only one of cases A, B or D - also appears to be challenging.

\subsection{Requirements for PMS in DIUs}

In the course of our interviews, some respondents raised issues that are not yet or insufficiently covered by RE1 to RE9, so we present three additional requirements for PMS in the specific context of DIUs. While some of them still have some connection to the ones identified in the literature, the intention here was to specifically reflect on the role of DIUs in their organisational context. RE3, for example, points out the importance of aligning PMS with corporate strategy, but does not contain any information on how this could be handled in DIUs. For this reason, RE11 takes a closer look at the role of PMS in relation to the idiosyncratic role of DIUs in the corporate context. Overall, the requirements presented here should be considered as an extension/adaptation of the PMS to the specific context of the DIUs. DIU members have often expressed these requirements as wishes, i.e., no implementation has taken place so far. An overview of the data and our coding can be found in Table 4.

RE10 - PMS for DIUs should incentivise employees to experiment and show their learnings (Cases A, B, C, D, E): In our data, we identified both how the desire for a PMS can incentivise employees to experiment more, but also their fear of PMS, as it can also show up failures. One of the fears was that a PMS with more specific metrics could reduce experimentation-prone activities, since failures would also have to be translated into metrics and thus be more clearly visible, which could lead to negative consequences. To address this problem, it would be particularly helpful to develop a PMS that makes both experimentation and failure visible and acknowledges them: "We also measure the number of pilots and MVPs per year. This shows how much one is 
Table 4. Sample quotes for new requirements

\begin{tabular}{|c|c|c|}
\hline $\begin{array}{l}\text { Second } \\
\text { Order Code }\end{array}$ & $\begin{array}{l}\text { First Order } \\
\text { Code }\end{array}$ & Representative Quote \\
\hline \multirow{4}{*}{$\begin{array}{l}\text { P-RE10: PMS } \\
\text { within the DIU } \\
\text { should } \\
\text { incentivize } \\
\text { employees to } \\
\text { experiment and } \\
\text { show their } \\
\text { learnings }\end{array}$} & $\begin{array}{l}\text { Show and } \\
\text { acknowledge } \\
\text { experimentation }\end{array}$ & $\begin{array}{l}\text { "We also measure the number of pilots and MVPs per year. } \\
\text { This shows how much we are experimenting. [...] It is also } \\
\text { psychologically important to us to acknowledge failed } \\
\text { projects." (Case B) }\end{array}$ \\
\hline & $\begin{array}{l}\text { Hypothesis driven } \\
\text { progress reporting }\end{array}$ & $\begin{array}{l}\text { "Once the target value is reached, we assume that our hypo- } \\
\text { thesis been validated positively. If it is not reached, we can see } \\
\text { if the target value was set too poorly or if the hypothesis could } \\
\text { not be confirmed. If the hypothesis cannot be positively } \\
\text { validated, we need to modify the product feature." (Case C) }\end{array}$ \\
\hline & $\begin{array}{l}\text { Drive and } \\
\text { facilitate personal } \\
\text { learning }\end{array}$ & $\begin{array}{l}\text { "The platform should therefore not only be a database but } \\
\text { also allow personal contact. This enables us to learn from } \\
\text { each other." (Case A) }\end{array}$ \\
\hline & $\begin{array}{l}\text { Incentivize to } \\
\text { show how failing } \\
\text { projects contribute } \\
\text { through learnings }\end{array}$ & $\begin{array}{l}\text { "[...] even the things that are unsuccessful have a certain } \\
\text { value. Somehow this value must be shown. Even if it doesn't } \\
\text { generate financial success, it can still add value in a different } \\
\text { way. I find it very difficult to define it as a KPI, but it seems to } \\
\text { be a very important point." (Case A) }\end{array}$ \\
\hline \multirow{3}{*}{$\begin{array}{l}\text { P-RE11: PMS } \\
\text { should help the } \\
\text { DIU and main } \\
\text { organisation to } \\
\text { exchange data } \\
\text { that allows the } \\
\text { DIU to pursue } \\
\text { tasks very } \\
\text { autonomously }\end{array}$} & $\begin{array}{l}\text { Closer } \\
\text { relationship } \\
\text { between lab and } \\
\text { mother company }\end{array}$ & $\begin{array}{l}\text { "It helps for the alignment and allows us a higher degree of } \\
\text { freedom. When we agree with each other and reach the set } \\
\text { goals, it creates trust. Later on, this gives us more autonomy } \\
\text { and a greater degree of freedom." (Case A) }\end{array}$ \\
\hline & $\begin{array}{l}\text { Independence and } \\
\text { Autonomy }\end{array}$ & $\begin{array}{l}\text { "We have no management guidelines. We formulate } \\
\text { hypotheses and target values." (Case C) }\end{array}$ \\
\hline & $\begin{array}{l}\text { Create trust that } \\
\text { allows for } \\
\text { autonomy }\end{array}$ & $\begin{array}{l}\text { "In the past, we were rather far removed from our core } \\
\text { business and thus had only limited contact with corporate. We } \\
\text { want to improve this in the future." (Case A) }\end{array}$ \\
\hline \multirow{2}{*}{$\begin{array}{l}\text { P-RE12: PMS } \\
\text { data should be } \\
\text { credible and } \\
\text { meaningful. }\end{array}$} & $\begin{array}{l}\text { Metrics should be } \\
\text { objective and have } \\
\text { a meaning }\end{array}$ & $\begin{array}{l}\text { "I wonder how the data is created in this tool. The numbers } \\
\text { must be realistic, so the data should not be entered by a } \\
\text { person. The data validation is also a central point." (Case A) }\end{array}$ \\
\hline & $\begin{array}{l}\text { Data Input needs } \\
\text { to be credible }\end{array}$ & $\begin{array}{l}\text { "Especially the internal stakeholders are important for a lab. I } \\
\text { formulated soft hypotheses such as " } 100 \text { customers in } 4 \\
\text { months to confirm the success of the pilot". But that doesn't } \\
\text { really say much either, because it's very easy to influence that } \\
\text { via the ads budget." (Case E) }\end{array}$ \\
\hline
\end{tabular}

trying out. [...]It is also psychologically important to acknowledge the failed projects." (Case B). Failure must be seen as a learning opportunity, whereby PMS can support "learning from each other" within the DIU and also act as a common database/knowledge base inviting closer communication between employees: "The platform should therefore not only be a database but also allow personal contact. That way you can learn from each other" (Case A). However, it is not easy to find appropriate metrics for inputs that do not provide direct financial value as another interviewee from Case A admitted: "[...] even the things that are not successful have a certain value. Somehow this value must be shown. Even if it doesn't generate financial success, it can still add value in a different way. I find it very difficult to define it as a KPI, but it seems to be a very important point."

RE11 - PMS should help the DIU and the main organisation to exchange data that allows the DIU to pursue tasks autonomously (Cases A, C, D): Another issue raised during the interviews was the relationship between a DIU and its parent organisation. 
Depending on whether a DIU operates in proximity to the core business and is more involved in the main organisation's processes or, conversely, is further away from it, the requirements for a PMS are different. One interviewee, for example, explained: "We have no management guidelines. We formulate hypotheses and these get target values." (Case C). The DIU in the quote thus appears to be very independent and has set up its own performance measurement - including its own metrics - which is separate from the parent organisation. Another case that has already gone through this phase explains, however: "In the past, we were rather far removed from our core business and thus had only limited contact with corporate. We want to improve this in the future." (Case A). This statement could indicate that there may be a learning curve with regard to the cooperation with the main organisation or that this relationship may experience different phases of proximity and distance. Another person working for the same DIU - Case A - explained their learnings and the meaning of the PMS: "It helps in terms of alignment and allows us a higher degree of freedom. When we agree with each other and we reach the goals, it creates trust. Later on, this gives us more autonomy and a greater degree of freedom." This view about a PMS is quite interesting because the employee in question obviously understands the use of a PMS as a mechanism that allows a higher degree of freedom for the DIU.

RE12 - PMS data should be credible and meaningful (Cases A, B, E): Although this requirement may seem obvious at first sight, it takes on a new importance in the context of DIUs. Their specific activities - mostly in the early phase of innovation - make it difficult to apply standard metrics, which forces DIUs to identify and collect the relevant data for performance measurement themselves. This poses the challenge that the credibility of the data may be lower, as one respondent mentioned: "I wonder how the data is created in this tool. The numbers must be realistic, so the data should not be entered by a person. Data validation is also a key point." (Case A). With regard to the above, another interviewee mentioned the danger of manipulating metrics, so that it is necessary to agree on appropriate metrics and to make their underlying background transparent in each case: "Especially the internal stakeholders are important for a lab. I then formulated soft hypotheses such as '100 customers in 4 months to confirm the success of the pilot'. But that doesn't really say much either, because it's very easy to influence that via the ads budget." (Case A). While this may be the case for many metrics used by organisations, the risk may be greater in the context of a DIU with its greater freedom and the desire/need to report favourable metrics to the main organisation

\section{Discussion}

We argue that the implementation of a PMS for DIUs offers both the possibility to prevent failure or even its abolishment - by for example addressing the challenge of unclear DIU objectives [8] - and to make their success and thus their value contribution visible to the main organization - as already mentioned in previous studies $[4,5]$. In order to create the basis for such a system our research is aimed at identifying its requirements in the context of DIUs. We answer RQ1 by giving an overview of the 
requirements that the literature places on PMS for (digital) innovation and agile working and show how these have been confirmed in practice. However, the actual implementation is very uneven. Furthermore, DIUs have additional requirements for a PMS that are currently not - or only sufficiently - dealt with in the literature, which is why we have proposed three new requirements that relate specifically to DIUs, and thus answer RQ2. In the discussion, we want to reflect three implications on the use of PMS in DIUs, which build on our analysis of these requirements.

PMS and their role in managing autonomy and freedom of DIUs

Existing literature on DIUs suggest that the freedom and the autonomy of a DIU depends on its organisational setup [5]. While some DIUs are an integral part of the main organisation, others are set up with much higher degrees of independence regarding their operations and management sometimes even located offsite [5]. As stated by Barthel et al. [5], tight coupling is beneficial for DIUs that focus on internal process improvements while looser coupling is helpful for innovation activities that are further away from the main organisation's core business [5]. Considering our findings, we propose that PMS can be seen as a mechanism to manage the relationship between the DIU and the main organisation. Our data suggest that loosely coupled DIUs, which are more likely to develop completely new innovation, have a learning curve that may bring them closer to the main organisation as they progress. Statements from "younger" DIUs (age two to three years) show that they are given lots of freedom, and employees tend to enjoy this freedom being less concerned with strategic alignment with the main organisation and measuring their activities. This is in line with the findings from Raabe et al. [8] who state that some DIUs lack clear objectives. However, once they have gained experience in their day-to-day work, some DIU might conclude that closer coordination is needed in order to be perceived as valuable by the main organisation (Case A). One of our respondents explained, he sees a PMS as a tool that helps to align with the main organisation's strategy and build trust, which in turn allows the DIU more freedom in its innovation efforts.

\section{Level of PMS adoption in DIUs}

Our results show that the majority of DUIs considered is aware of the theoretical requirements of a PMS for digital innovation. However, RE1 and RE2 in particular, as well as RE5, RE7, RE8 and RE9 (when excluding training cases B and C) are usually not yet operational, although this is only partly due to a lack of willingness. Most respondents would certainly like to use more metrics than they have done so far and generally have a very positive attitude towards PMS. This is particularly evident in the three new requirements we have introduced. The challenge many of them face, however, is to find the "right" metrics for their sometimes highly exploratory activities. Translating these activities into an understandable meaningful metric has not yet been done sufficiently. Conversely, however, there seems to be a concern that if you measure too much, you are too transparent and the main organisation might misjudge the innovation activities of the DIU. This is already addressed in a previous study which has found that there is a discrepancy between the actions of the DIUs and the way that the main organisation evaluates them [21]. Overall, there seems to be a perception that the current error culture does not allow mistakes to be seen as a normal consequence of innovation, which makes DIU vulnerable to attack by disclosing too many metrics. A 
third and more pragmatic reason for the lack of operationalised PMS requirements might be the maturity of the DIUs. Two of them existed for roughly two years by the time of data collection and as we mentioned earlier, some DIUs seem to be given more freedom in this initial phase potentially implementing more metrics later on sometimes also in the course of a stronger alignment with the main organisation.

Different measurement approaches of DIU and main organisation

Further room for discussion, partly related to the previous section, is provided by the fact that during the data analysis it seemed that the differences in the measurement approaches of DIU and main organisation are a challenge. Our data show that DIUs have already implemented some elements of a PMS, which are partly aligned with the agile practices they base their innovation work on [3]. In some cases, the DIU adopted specific measurements related to those practices such as e.g., tracking the amount of hypothesis validated or counting the number of pilot customers won. The main organisation, on the other hand, continues to work with familiar performance measurement metrics, which means that two different approaches now have to be reconciled. This is anything but trivial as shown by Mayer et al. [21] who found that contact between the DIU and the main organisation can be problematic if, for example, activities of DIUs try to be adopted from the main organisation. This raises the question of governance mechanisms that are capable of increasing the alignment between DIUs and the main organisation, both by developing precise goals for the DIUs and by translating these into concrete fields of action. It is also necessary to ensure that these goals are met, i.e., that the associated process is monitored. Our results indicate that PMS play an important role in this process, but also that their impact is limited if DIUs' objectives are poorly defined.

\section{Conclusion}

We answer RQ1 by first conducting a literature review and identify the requirements for a PMS for DIU. In a second step, we conduct five case studies with DIUs and analysed whether the requirements from the literature are confirmed and adopted in practice. Regarding RQ2 we propose three new requirements derived from the interviews to broaden the knowledge of PMS for DIUs. We discuss our findings along three implications: The role of PMS in managing autonomy and freedom of DIUs, the level of PMS adoption in DIUs, and the challenges coming from different measurement approaches of DIUs and the main organisation. We see our research both as a starting point to develop more sufficient PMS that help DIUs to measure their activities and as a basis for discussion on quantitative evidence of how successful DIUs are as "fast lanes" for (digital) innovation [5]. Furthermore, we shed light on how to measure the development of digital innovation in general [10]. Due to the increasing customer orientation in their development, research also demands new measuring methods. Our results underline the relevance of agile methods in this context and the need to capture them using a new measurement approach and specific metrics that differ from those previously used in large organisations. Practitioners can use our research to compare their performance measurement with it and consider possible adjustments. In particular, 
we advise them to clarify objectives early on and translate them into metrics and indicators that can help both the DIU and the main organisation to clearly manage expectations.

Of course, our study is not without limitations. The small sample size and the geographical limitation to companies in Germany and Switzerland does not allow for a generalisation of the results. Future research could extend our results by using a larger sample, specify them by focusing on a particular industry or by highlighting certain demands on PMS according to the different objectives of a DIU e.g., by Fuchs et al [7]. Furthermore, we have ensured to interview people with different roles within the DIU, both those whose work is to be measured by the PMS (DIU employees) and those who want to measure the performance of the DIU (e.g., head of innovation). Nevertheless, all interview partners had a direct connection to the DIU and are therefore potentially biased. It would be helpful in future studies to also interview people who have a greater distance to the DIU and who potentially evaluate their work/work results differently, such as members of the top management (CEO, CFO, etc.) or representatives of other departments that cooperate with the DIU. The requirements we present could also be investigated specific types of DIUs closer and analyse requirements at this level.

\section{Acknowledgement}

We kindly thank Céline Stalder for her support in gathering data and the Hasso Plattner Design Thinking Research Program for funding our research generously.

\section{References}

1. Yoo, Y., Henfridsson, O., Lyytinen, K.: Research Commentary-The New Organizing Logic of Digital Innovation: An Agenda for Information Systems Research. Information Systems Research. 21, 724-735 (2010).

2. Vial, G.: Understanding digital transformation: A review and a research agenda. The Journal of Strategic Information Systems. 28, 118-144 (2019).

3. Holotiuk, F., Beimborn, D.: Temporal Ambidexterity: How Digital Innovation Labs Connect Exploration and Exploitation for Digital Innovation. In: ICIS 2019 Proceedings. Munich (2019).

4. Hund, A., Holotiuk, F., Wagner, H.-T., Beimborn, D.: Knowledge Management in the Digital Era: How Digital Innovation Labs Facilitate Knowledge Recombination. In: ECIS 2019 Proceedings. Stockholm (2019).

5. Barthel, P., Fuchs, C., Birner, B., Hess, T.: Embedding Digital Innovations in Organizations: A Typology for Digital Innovation Units. In: Conference Proceedings. pp. 780-795. Potsdam (2020).

6. Viki, T.: Pirates In The Navy: How Innovators Lead Transformation. Unbound Publishing (2020).

7. Fuchs, C., Barthel, P., Herberg, I., Berger, M., Hess, T.: Characterizing Approaches to Digital Transformation: Development of a Taxonomy of Digital Units. In: Conference Proceedings. Siegen (2019). 
8. Raabe, J.-P., Horlach, B., Schirmer, I., Drews, P.: 'Forewarned is Forearmed': Overcoming Multifaceted Challenges of Digital Innovation Units. In: AMCIS 2020 Proceedings. Virtual (2020).

9. Koen, P., Ajamian, G., Burkart, R., Clamen, A., Davidson, J., D’Amore, R., Elkins, C., Herald, Kathy, Incorvia, M., Johnson, A., Karol, R., Seibert, R., Slavejkov, A., Wagner, K.: Providing Clarity and A Common Language to the "Fuzzy Front End." ResearchTechnology Management. 44, 46-55 (2001).

10. Hund, A., Drechsler, K., Reibenspiess, V.A.: The current state and future opportunities of digital innovation: A literature review. In: ECIS 2019 Proceedings. Stockholm (2019).

11. Huang, J., Henfridsson, O., Liu, M.J., Newell, S.: Growing on steroids: Rapidly scaling the user base of digital ventures through digital innovation. Miss. Q. 41, (2017).

12. Kerssens-van Drongelen, I.C., Cooke, A.: Design principles for the development of measurement systems for research and development processes. R\&D Management. 27, 345357 (1997).

13. Schermann, M., Wiesche, M., Krcmar, H.: The Role of Information Systems in Supporting Exploitative and Exploratory Management Control Activities. Journal of Management Accounting Research. 24, 31-59 (2012).

14. Ylinen, M., Gullkvist, B.: The effects of organic and mechanistic control in exploratory and exploitative innovations. Management Accounting Research. 25, 93-112 (2014).

15. Bedford, D.S., Bisbe, J., Sweeney, B.: Performance measurement systems as generators of cognitive conflict in ambidextrous firms. Accounting, Organizations and Society. 72, 21-37 (2019).

16. Kohli, R., Melville, N.P.: Digital innovation: A review and synthesis. Information Systems Journal. 29, 200-223 (2019).

17. Nambisan, S., Lyytinen, K., Majchrzak, A., Song, M.: Digital innovation management: Reinventing innovation management research in a digital world. Miss. Q. 41, 223-238 (2017).

18. Svahn, F., Mathiassen, L., Lindgren, R.: Embracing Digital Innovation in Incumbent Firms: How Volvo Cars Managed Competing Concerns. Miss. Q. 41, (2017).

19. Gimpel, H., Hosseini, S., Huber, R.X.R., Probst, L., Röglinger, M., Faisst, U.: Structuring Digital Transformation: A Framework of Action Fields and its Application at ZEISS. J. Inf. Technol. Theory Appl. 19, 3 (2018).

20. Frey, J., Holotiuk, F., Beimborn, D.: Debating Digital Innovation: A Literature Review on Realizing Value from Digital Innovation. In: Conference Proceedings. Potsdam (2020).

21. Mayer, S., Haskamp, T., de Paula, D.: Measuring what Counts: An Exploratory Study about the Key Challenges of Measuring Design Thinking Activities in Digital Innovation Units. In: Proceedings of the 54nd HICSS. 2021. Virutal (2021).

22. Berghaus, S., Back, A.: Disentangling the Fuzzy Front End of Digital Transformation: Activities and Approaches. In: ICIS 2017 Proceedings. pp. 1-17. Seoul (2017).

23. Dziallas, M., Blind, K.: Innovation indicators throughout the innovation process: An extensive literature analysis. Technovation. 80-81, 3-29 (2019).

24. Dechow, N., Mouritsen, J.: Enterprise resource planning systems, management control and the quest for integration. Accounting, Organizations and Society. 30, 691-733 (2005).

25. Vom Brocke, J., Simons, A., Niehaves, B., Riemer, K., Plattfaut, R., Cleven, A., Others: Reconstructing the giant: on the importance of rigour in documenting the literature search process. In: ECIS 2009 Proceedings. pp. 2206-2217. Verona (2009).

26. Yin, R.K.: Case study research: Design and methods. Sage publications. Thousand oaks. (2009). 
27. Gioia, D.A., Corley, K.G., Hamilton, A.L.: Seeking Qualitative Rigor in Inductive Research: Notes on the Gioia Methodology. Organizational Research Methods. 16, 15-31 (2013).

28. Miles, M.B., Huberman, A.M., Saldana, M.R.J.: Qualitative Data Analysis. Sage Publications, Christchurch, New Zealand (2013).

29. Globerson, S.: Issues in developing a performance criteria system for an organization. Int. J. Prod. Res. 23, 639-646 (1985).

30. Neely, A., Mills, J., Platts, K., Richards, H., Gregory, M., Bourne, M., Kennerley, M.: Performance measurement system design: developing and testing a process-based approach. Int. J. Oper. Prod. Manage. 20, 1119-1145 (2000).

31. Lill, P., Wald, A., Munck, J.C.: In the field of tension between creativity and efficiency: a systematic literature review of management control systems for innovation activities. Eur. J. Innov. Manag. ahead-of-print, (2020).

32. Wiesche, M., Bodner, J., Schermann, M.: Antecedents of IT-Enabled Organizsational Control Mechanisms. In: ECIS 2012 Proceedings. Barcelona (2020).

33. Hamilton, S., Chervany, N.L.: Evaluating Information System Effectiveness - Part II: Comparing Evaluator Viewpoints. Miss. Q. 5, 79-86 (1981).

34. Henttonen, K., Ojanen, V., Puumalainen, K.: Searching for appropriate performance measures for innovation and development projects. R\&D Management. 46, 914-927 (2016).

35. Micheli, P., Manzoni, J.-F.: Strategic Performance Measurement: Benefits, Limitations and Paradoxes. Long Range Planning. 43, 465-476 (2010).

36. Barros, R.S., da Costa, A.M.D.S.: Bridging management control systems and innovation. Qualitative Research in Accounting \& Management. 16, 342-372 (2019).

37. Curtis, E., Sweeney, B.: Managing different types of innovation: mutually reinforcing management control systems and the generation of dynamic tension. Accounting and Business Research. 47, 313-343 (2017).

38. Davila, A., Foster, G., Oyon, D.: Accounting and Control, Entrepreneurship and Innovation: Venturing into New Research Opportunities. European Accounting Review. 18, 281-311 (2009).

39. Chiesa, V., Frattini, F., Lamberti, L., Noci, G.: Exploring management control in radical innovation projects. European Journal of Innovation Management. 12, 416-443 (2009).

40. Said, A.A., HassabElnaby, H.R., Wier, B.: An Empirical Investigation of the Performance Consequences of Nonfinancial Measures. Journal of Management Accounting Research. 15, 193-223 (2003).

41. Adams, R., Bessant, J., Phelps, R.: Innovation management measurement: A review. International Journal of Management Reviews. 8, 21-47 (2006).

42. Urbach, N., Ahlemann, F., Böhmann, T., Drews, P., Brenner, W., Schaudel, F., Schütte, R.: The impact of digitalization on the IT department. Business \& information systems engineering. 61, 123-131 (2019).

43. Brynjolfsson, E., Oh, J.: The Attention Economy: Measuring the Value of Free Digital Services on the Internet. In: ICIS 2012 Proceedings. Orlando (2012).

44. Boerman, M.P., Lubsen, Z., Tamburri, D.A., Visser, J.: Measuring and Monitoring Agile Development Status. In: 2015 IEEE/ACM 6th International Workshop on Emerging Trends in Software Metrics. pp. 54-62 (2015).

45. Lee, J.Y.H., Hsu, C., Silva, L.: What Lies Beneath: Unraveling the Generative Mechanisms of Smart Technology and Service Design. Journal of the Association for Information Systems. 21, 1621-+ (2020).

46. Basili, V., Heidrich, J., Lindvall, M., Münch, J., Regardie, M., Rombach, D., Seaman, C., Trendowicz, A.: Bridging the gap between business strategy and software development. ICIS 2007 Proceedings. Montreal \& Québec (2007). 